\title{
8
}
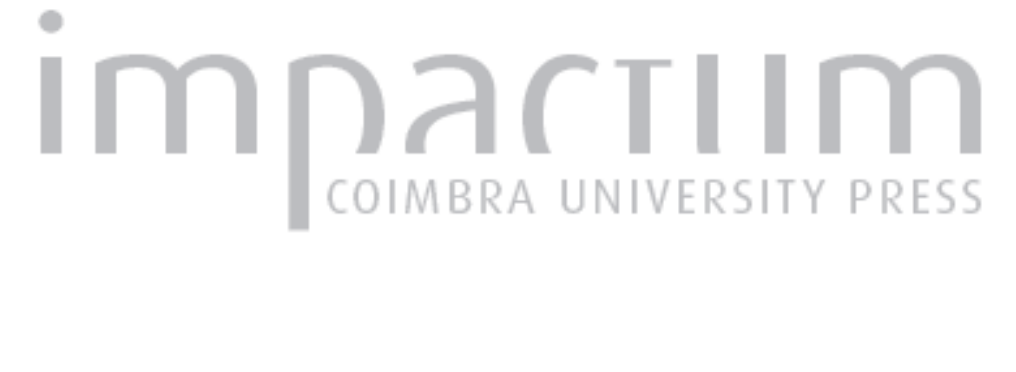

\section{O imaginário grego na escultura neoclássica de Christian Daniel Rauch: o tema de Jasão e Medeia}

\author{
Autor(es): $\quad$ Castro Filho, Cláudio
} Publicado por: Associação Portuguesa de Estudos Clássicos; Instituto de Estudos

URL

persistente:

URl:http://hdl.handle.net/10316.2/30320

DOI:

DOI:http://dx.doi.org/10.14195/0872-2110_56_10

Accessed : $\quad$ 26-Apr-2023 10:39:18

A navegação consulta e descarregamento dos títulos inseridos nas Bibliotecas Digitais UC Digitalis, UC Pombalina e UC Impactum, pressupõem a aceitação plena e sem reservas dos Termos e Condições de Uso destas Bibliotecas Digitais, disponíveis em https://digitalis.uc.pt/pt-pt/termos.

Conforme exposto nos referidos Termos e Condições de Uso, o descarregamento de títulos de acesso restrito requer uma licença válida de autorização devendo o utilizador aceder ao(s) documento(s) a partir de um endereço de IP da instituição detentora da supramencionada licença.

Ao utilizador é apenas permitido o descarregamento para uso pessoal, pelo que o emprego do(s) título(s) descarregado(s) para outro fim, designadamente comercial, carece de autorização do respetivo autor ou editor da obra.

Na medida em que todas as obras da UC Digitalis se encontram protegidas pelo Código do Direito de Autor e Direitos Conexos e demais legislação aplicável, toda a cópia, parcial ou total, deste documento, nos casos em que é legalmente admitida, deverá conter ou fazer-se acompanhar por este aviso.

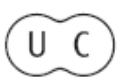




\section{Boletim de \\ Estudos Clássicos}

Associação Portuguesa de Estudos Clássicos Instituto de Estudos Clássicos

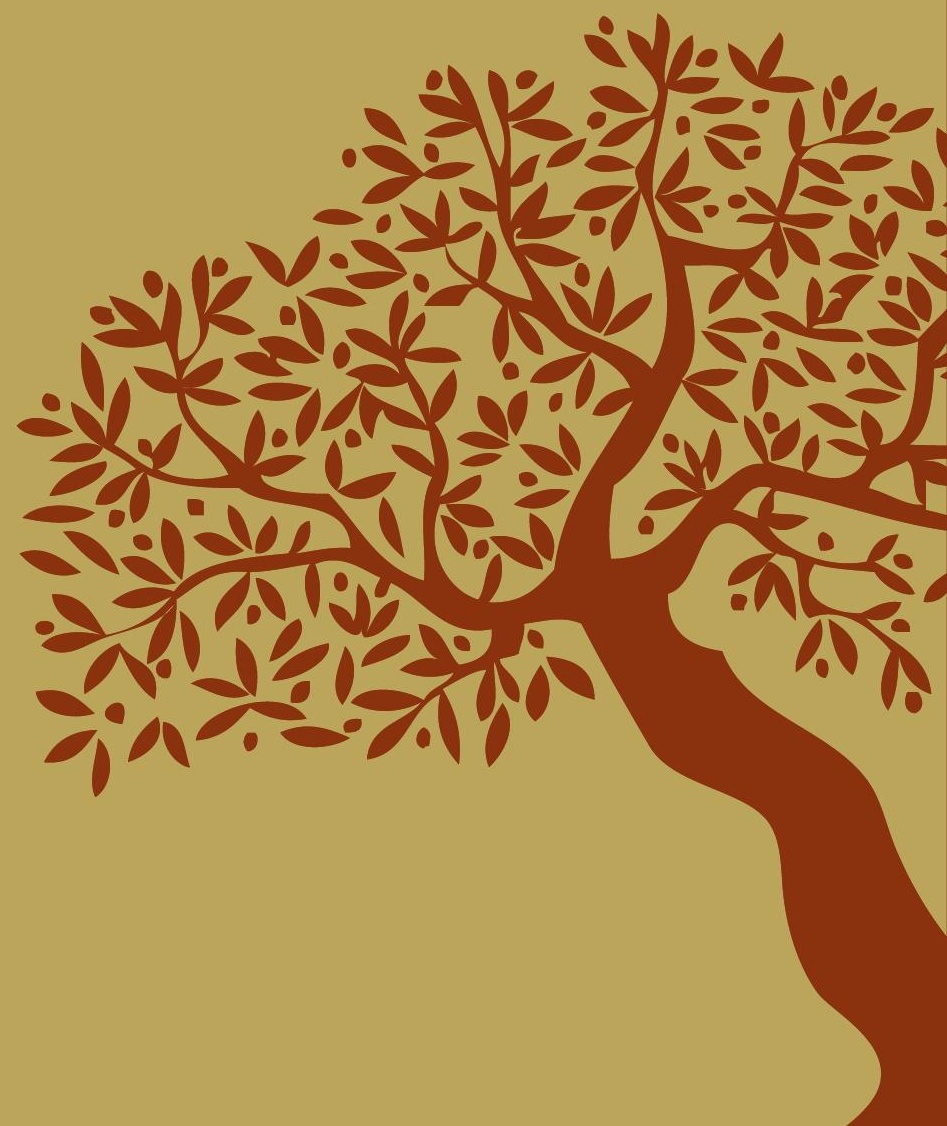

Coimbra

Dezembro de 2011 


\section{O IMAGINÁRIO GREGO NA ESCULTURA NEOCLÁSSICA DE Christian Daniel Rauch: O Tema de Jasão e Medeia}

\section{Sobre o artista}

Christian Daniel Rauch (2 de janeiro de 1777 - 3 de dezembro de 1857), escultor alemão, é natural de Arolsen, parte do então principado de Waldeck. Procede de uma família pobre, que não pôde proporcionar a formação necessária à lapidação de suas habilidades para a arte, situação social que deu a sua trajetória um caráter particular. Parte para Berlin já em 1797 e consegue um emprego simplório na corte, como lacaio, o que lhe garante custear a prática da escultura nas horas vagas. Certa vez, é surpreendido, enquanto realizava uma de suas modelagens em cera, justamente pela rainha Luísa da Prússia. Está, em definitivo, mudada a sua sorte.

Dona Luísa o envia para a Academia das Artes (Akademie der Künste) e, em 1804, Rauch parte para a Itália, onde completará sua formação. Em Roma, travará amizade com grandes figuras da cultura de seu tempo, como Wilhelm von Humboldt, Antonio Canova e Bertel Thorvaldsen. É interessante observar a importância que as viagens de formação, nomeadamente a viagem a Roma, têm no contexto da moderna Alemanha. Um bom exemplo dessa prática cultural está registrado na Viagem à Itália de Goethe. A Península Itálica, compreendida em sua totalidade como principal legado arqueológico da Magna Grécia, será a principal fonte de inspiração do projeto nacional prussiano, que buscará forjar a identidade cultural alemã a partir de influxos trazidos do Mediterrâneo. Sendo Goethe figura referencial nesta passagem dos séculos XVIII para o XIX, não é de se estranhar que Christian Daniel Rauch integre, na Alte Nationalgalerie Berlin, uma coleção que dá visibilidade aos chamados "artistas da Era de Goethe".

Sua fama, porém, pode ser contada a partir de 1811, quando recebe, da rainha Luísa, a encomenda de um monumento: trata-se de uma estátua que representa a monarca numa postura de sono, para ser instaurada num mausoléu de Charlottenburg. O êxito da obra (realizada, provavelmente, já entre 1818 e 1827) é tamanho que, a partir daí, praticamente todas as estátuas públicas passam a ser confiadas a Rauch. Destaquemos, para não nos 
estendermos em incontáveis exemplos, apenas a estátua de Dürer, em Nuremberg, e a estátua de Kant, em Königsberg. A obra de Christian Daniel Rauch está, portanto, diretamente relacionada à afirmação do projeto cultural prussiano, tanto em seu estilo (a estatuária neoclássica) quanto em sua temática (os motivos mitológicos e religiosos).

\section{Rauch da coleção Alte Nationalgalerie Berlin: o relevo de Jasão e Medeia}

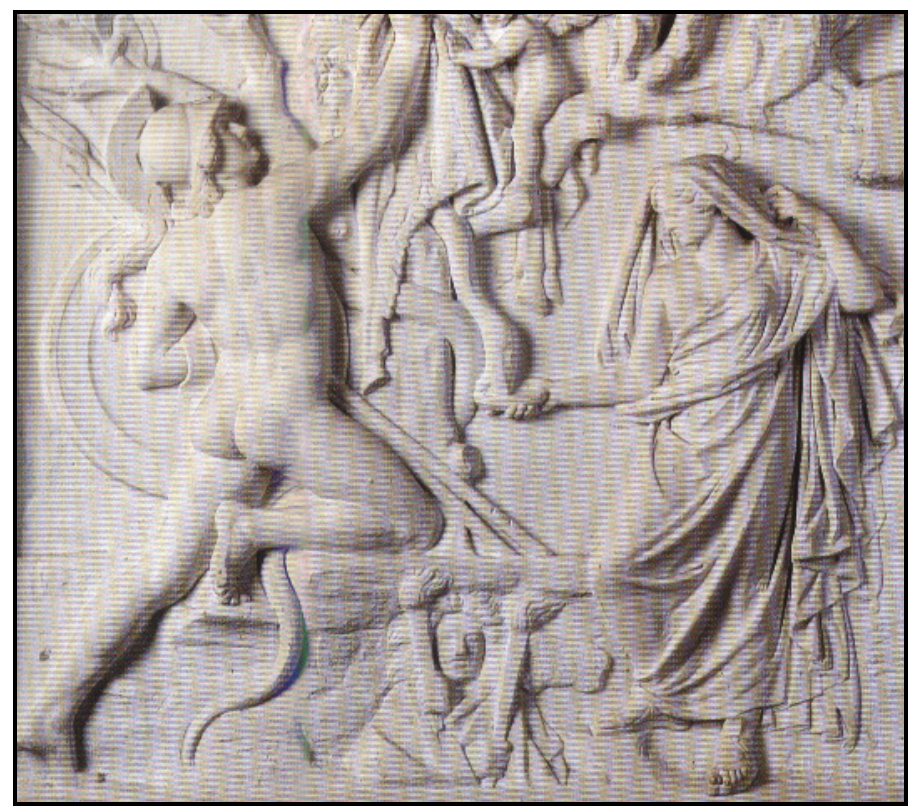

O relevo Jasão e Medeia, iniciado por Rauch a partir de 1805, e sobre o qual o artista provavelmente voltou a trabalhar em 1818, é uma obra inacabada, realizada em mármore, medindo 48,5 por $55 \mathrm{~cm}$. É, portanto, uma peça ligeiramente retangular, que retoma a forma dos frisos dos antigos templos gregos. Encontra-se hoje na Alte Nationalgalerie Berlin, mas pertence inicialmente ao Rauch Museum.

A cena representada neste relevo rememora o momento em que Jasão recolhe o Velocino de Ouro, um dos mais célebres episódios do ciclo argonáutico. A habilidade narrativa de Rauch fica evidente nesta obra, pois consegue concentrar plasticamente detalhes narrativos que, nas diversas 
fontes literárias do mito, não se dão simultaneamente, embora pertençam a um mesmo ciclo. Por esta exímia capacidade de articulação narrativa, resultando numa imagem única, é que vemos, na cena, a influência de Amor (Eros, Cupido) - que, aliás, ganha uma interpretação um tanto quanto angelical, dando certo ar cristão à obra - sobre a ação de Medeia.

Como sabemos, a princesa da Cólquida, uma vez flechada pela paixão, usa seus poderes mágicos para ajudar Jasão na conquista do Velo que, assim esperava, lhe garantiria o trono de Iolcos, então usurpado por seu tio Pélias. Por esta razão, vemos na cena de Rauch a princesa a alimentar, com uma poção entorpecente, o dragão que vigia a pele sagrada, permitindo que Jasão o furte. Vemos ainda Hécate (na parte inferior do relevo) - deusa dos caminhos, das artes mágicas, dos espíritos dos mortos -, integrante da genealogia de Medeia, e que aqui ocupa o lugar que também simboliza, qual seja, o mundo subterrâneo.

Esta obra é, portanto, um bom exemplo do caráter maneirista que tanto se manifesta em obras do período neoclássico, tendo em vista a dinâmica de contrastes que permite ao artista atingir certa noção de equilíbrio. A oposição entre o masculino (a figura de Jasão, de costas, do lado esquerdo) e o feminino (a figura de Medeia, frontalmente disposta, do lado direito) é a mais visível de tais oposições. Mas há também a oposição entre Hécate (figura subterrânea, disposta na parte inferior) e Amor (figura celeste, aqui angelical, situada na parte superior). Considere-se ainda a combinação entre dois diferentes tempos - (1) o entorpecimento do dragão e (2) o furto do Velocino -, que aqui conjugam, em simultâneo, duas ações distintas. Pode-se ainda falar da oposição entre elementos pagãos (a mitologia clássica), de um lado, e elementos cristãos, de outro, já que há uma nítida alusão ao tema do pecado original, tendo em vista inclusive que a cena se estrutura a partir de uma árvore: o dragão representando a Serpente, o Velocino como fruto proibido, Jasão como Adão, Medeia no lugar de Eva. O texto de Bernard Maaz (2001: 38), editor do volume do Prestel Museum Guide dedicado à Alte Nationalgalerie, assim destaca esta obra no contexto da produção de Rauch:

The reference to themes from antiquity, as well as to a successful statue of Jason that Thorvaldsen had made not long before, plus the fact that this was not a commissioned work, all show that first and foremost Rauch wanted this work to demonstrate his creative powers and that, at the same time, he wanted to measure himself as much 
against the sculptors one of the most highly esteemed sculptors of his day.

O relevo em torno do tema de Jasão e Medeia insere-se na produção de Rauch, pois, como indício de um processo de criação próprio, marcado pela autodisciplina de um artista cujo amadurecimento técnico e poético esteve muito ligado a um percurso solitário de aprendizagem. A criatividade é trabalhada, assim, como capacidade subjetiva de reinterpretar plasticamente todo um imaginário antigo, todo um repertório cultural em muito ligado aos anseios pangermânicos de então. Na perspectiva de um projeto cultural e de uma identidade nacional prussiana, a Alemanha procura chamar para si um legado europeu que possa trazer ao Norte os salutares ventos do Mediterrâneo. A idealizada Magna Grécia, experienciada nas viagens de formação à Itália e florescentemente registada na historiografia de Winckelmann, reinventa-se como paradigma de modernidade.

Considerando ainda os acentuados contrastes que marcam a representação do tema de Jasão e Medeia nesta versão rauchiana, vale a pena observar o caráter neomaneirista presente, pois, na produção neoclássica. Observa Gustavo Schnoor (2003: 177) que "a longa duração do Maneirismo (...) iria colocá-lo em contato, quase em continuidade, com o advento do gosto neoclássico, que se voltou para os modelos de sua própria tradição clássica, ou seja, para o Maneirismo, antes de interessar-se por Roma Antiga, pela Grécia ou pelo Renascimento".

Assim como sua Vitória (obra realizada entre 1838 e 1845) - disposta sentada, com asas monumentalmente abertas e segurando uma guirlanda de louros - representa não só uma simples retomada do motivo clássico, mas serve de pretexto para celebrar as vitórias militares da Prússia, o tema de Jasão e Medeia insere-se neste percurso em que a releitura do passado grego interpreta metaforicamente certa visão acerca da realidade em tempo presente. Ser neoclássico é, portanto, ser moderno, com todas as implicações estéticas e com todos os limites do comprometimento ideológico que a criação artística carrega no ambiente de tão fulgurante corte europeia, como a de Friedrich II e Luise von Preussen.

\section{A questão do neoclássico}

Giulio Carlo Argan (1994: 144) entende o termo ‘clássico’ não como um estilo de época em específico, mas como uma atitude artística recorrente em diversos momentos culturais, tendo em comum o reportar-se a um passado 
que, por ser exemplar, é inspirador. Este passado dirá sempre respeito, em alguma medida, à "Grécia de Péricles e Fídias, no auge de sua civilização". Sendo assim, um dos principais problemas que movimentam a história da arte consiste em perceber a "alternância de diversos tipos de classicismo".

O caso maneirista, a partir do século XVI, é um bom exemplo em que tal alternância se manifesta, tanto que atinge o nível do paradoxo. "Certos protagonistas do Maneirismo recorrem ao mundo antigo através de fontes diversas" (Argan \& Fagiolo 1994: 145), entretanto tal fenômeno se concretiza artisticamente mediante explícitas antíteses. Em vez do equilíbrio, da proporcionalidade e da simetria que caracterizaram boa parte das obras do século V a.C., bem como do Pleno Renascimento, o que está em causa é o jogo de tensões entre o clássico e o anticlássico - nas palavras de Shakespeare, um maneirista na poesia dramática, "ser ou não ser, eis a questão".

Mas, também para Argan, será no momento neoclássico, já no século XIX, que o recurso à antiguidade se tornará essencial à arte, não só do ponto de vista da produção artística (com destaque para a pintura de David e a escultura de Canova), mas igualmente da produção teórica (que terá em Winckelmann seu maior expoente). Já aqui um primeiro problema conceitual se coloca, tendo em vista a indiferenciação, por parte da teoria, do que diz respeito à Grécia, de um lado, e a Roma, de outro. Os textos de Winckelmann são um ilustrativo exemplo de tal emaranhado, já que, no tocante ao legado cultural do território italiano, não só o alemão não distingue o que é grego do que é romano, como também confunde obras da antiguidade com obras já renascentistas. Ou seja, a indistinção passa não só pelo espaço, mas também pelo tempo.

Além disso, por ser considerada retrógrada em face dos ideais iluministas - que, ao destacarem a criação legítima em detrimento da interpretação do passado, deslocam a arte da esfera aristocrática para a burguesa -, a arte neoclássica, no panorama dos movimentos modernos alavancados no Oitocentos, passa a ser vista num segundo plano. Neste sentido, desde as últimas décadas do século XX temos assistido a uma revisão crítica do movimento, tendo em vista seu contributo como gesto inaugural dos movimentos modernos a seguir. Assim situam Argan \& Fagiolo tais questões:

Também a arte do período neoclássico tem sofrido, até aos nossos dias, uma pesada desvalorização. Apreciava-se a posição cultural, mas 
ela era fortemente considerada não-arte: ignorava-se o problema da descoberta de uma arte já não criativa mas sim crítica e o problema da ideologia iluminista (e por isso revolucionária). A confirmação do actual sucesso do período surgiu em 1972 com uma grande exposição em Londres, The Age of Neo-Classicism (...). Muitos aspectos do fenômeno ainda estão para ser aprofundados, até por causa da recente viragem crítica (Argan \& Fagiolo 1994: 71-72).

Ou seja, se o neoclassicismo não foi um fenômeno artístico de inteira ruptura com o cânone tradicional (tal e qual preconizarão as vanguardas modernas), tampouco foi um período de mera conformidade, uma vez que se reporta sim ao passado grecoromano, mas o faz de forma crítica, reinterpretando-o num novo contexto cultural.

\section{Referências bibliográficas:}

G. C. ARGAN \& M. FAGIOLO, Maurizio (1994). Guia de História da Arte. Tradução M. F. Gonçalves de Azevedo. Lisboa, Editorial Estampa.

B. MAAZ (ed.) (2001). “Alte Nationalgalerie Berlin”. In: Prestel Museum Guide. Translated by Fiona Elliot and Almuth Seebohm. Munich [etc.], Prestel, 2001.

G. SCHNOOR (2003). “O Maneirismo no Brasil". In: Concinnitas: revista do Instituto de Artes da UERJ, número 5, dez. 2003.

\section{Sítios em Internet:}

Verbete na Enciclopédia Britânica:

http://www.britannica.com/EBchecked/topic/492167/Christian-Daniel-

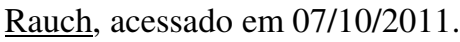

Christian Daniel Rauch Museum:

http://www.museum-bad-arolsen.de/rauch_museum.php, acessado em 07/10/2011.

Blog August Rudolf Wild: www.august-wild.de, acessado em 07/10/2011. 